\title{
Selective disruption of muscle and brain-specific BPAG 1 isoforms in a girl with a 6;15 translocation, cognitive and motor delay, and tracheo-oesophageal atresia
}

\author{
R Giorda, A Cerritello, M C Bonaglia, S Bova, G Lanzi, E Repetti, S Giglio, C Baschirotto, \\ T Pramparo, L Avolio, R Bragheri, P Maraschio, O Zuffardi
}

J Med Genet 2004;41:e71 (http://www.jmedgenet.com/cgi/content/full/41/6/e71). doi: 10.1136/jmg.2003.012260

T he protein BPAG1 (MIM: 113810, 600088, http:/ www.ncbi.nlm.nih.gov/Omim/)/Dystonin is a $230 \mathrm{kDa}$ hemidesmosomal protein belonging to the plakin family, originally identified as one of the major autoantigens of bullous pemphigoid (BP), an autoimmune subepidermal skin blistering disease. ${ }^{1}$ Mutations in the Dystonin gene result in sensory neuron degeneration in the mutant mouse (dystonia muscolorum $(\mathrm{dt} / \mathrm{dt})) .^{2-4}$

The complex organisation of the gene has gradually emerged, initially with the discovery of neuronal isoforms with different $\mathrm{NH} 2$-terminal sequences, ${ }^{356}$ and more recently with the demonstration of the existence of much longer brain- and muscle-specific isoforms with a complex $\mathrm{COOH}$-terminal organisation. ${ }^{78}$

Although a complete understanding of the variety of $B P A G 1$ isoforms has not been reached yet, a general picture of the organisation of the gene is now available. The epithelial isoform (BPAGle) is made of a coiled-coil (CC) rod domain flanked by an NH2-terminal head domain called the plakin domain, ${ }^{9}$ and by a COOH-terminal tail domain made of plectin repeats, capable of binding intermediate filaments (IF) and for this reason called the IF-binding domain (IFBD). ${ }^{9}$ The plakin domain binds BP180, the other major autoantigen in BP. ${ }^{10}$

The brain-specific isoform (BPAGla) has an NH2-terminal actin-binding domain (ABD) made of two calponin homology domains, ${ }^{35}$ a plakin domain, a series of spectrin repeats and a $\mathrm{COOH}$-terminal containing two EF-hand calciumbinding motifs, and a growth arrest-specific 2 (GAS2) microtubule-binding domain. ${ }^{71}$ An alternative NH2-terminal isoform produces a protein with a single calponin-homology domain, destroying the actin-binding activity and at the same time uncovering microtubule-binding activity. ${ }^{6}$

The muscle-specific isoform (BPAGIb) has a structure very similar to the brain isoform, but includes an additional central IFBD, encoded by a single large exon. ${ }^{78}$ The binding specificity of this domain has not been tested yet.

$B P A G 1 /$ Dystonin is a member of a family of giant cytoskeletal proteins showing properties of both the spectrin and plakin superfamilies, named spectraplakins. ${ }^{12}$ To this family also belong the mammalian MACF $1^{611}{ }^{13}{ }^{14}$ and the Drosophila short stop (shot) genes. ${ }^{15-20}$

Since spectraplakins are able to interact with all three cytoskeletal components (IF, microtubules, actin), their functions may include: crosslinking cytoskeletal filaments; linking the cytoskeleton to plasma membranes; organising the interaction between the cortical cytoskeleton and plasma membrane proteins to generate membrane subdomains; and acting as scaffolding proteins to recruit signalling proteins to sites of cytoskeletal activity (reviewed in Roper et al, 2002 ${ }^{12}$ ).

The obvious importance of each of these functions for the cell makes these genes good candidates for involvement in

\section{Key points}

- We report on a female child with oesophageal atresia (EA) and psychomotor retardation associated with a "de novo" reciprocal translocation $t(6 ; 15)(\mathrm{p} 11.2$; p12). The patient presents a non-progressive encephalopathy, severe motor and mental retardation, and delayed visual maturation. The $6 p$ breakpoint falls within the BPAGl gene selectively interrupting the two brain- and muscle-specific isoforms.

- BPAG1 codes for a hemidesmosomal protein belonging to the plakin family, originally identified as one of the major autoantigens of bullous pemphigoid (BP). Homozygous BPAG1 knock-out mice show neurodegenerative disease and develop progressive ataxia due to the degeneration of the sensory neurons. No mutations for BPAG1 have been reported so far in humans.

- We discuss the possibility that BPAG1 haploinsufficiency or abnormal expression may determine the phenotypical abnormalities of our patient.

different genetic pathologies. Indeed, Drosophila shot mutations are embryonic lethal when homozygous, generating defects in epidermal integrity, epidermal muscle attachments, axon outgrowth, dendritic branching, neuromuscular junctions, and sense organ development, and anastomosis of the tracheal branches. ${ }^{16} 181921-23$

Mice homozygous for BPAGl mutations suffer progressive degeneration of the sensory neurons. ${ }^{4}$ Defects in the function of Schwann cells ${ }^{24}$ and muscles ${ }^{25}{ }^{26}$ have also been reported. In addition, a knockout mutation eliminating the plakin domain-encoding exons (probably generating a null phenotype) has a skin blistering phenotype similar to the one found in the human disease epidermolysis bullosa simplex. ${ }^{4} \mathrm{~A}$ similar phenotype, epidermolysis bullosa simplex associated with muscular dystrophy, is caused by mutations in the

Abbreviations: $A B D$, actin-binding domain; $B P$, bullous pemphigoid; CC, coiled-coil; DMEM, Dulbecco's modified Eagle medium; EA oesophageal atresia; EBV, Epstein-Barr virus; FBS, fetal bovine serum; FISH, fluorescent in situ hybridisation; FSHD, facioscapulohumeral muscular dystrophy; HAT, hypoxantine-aminopterin-thymidine; IF, intermediate filaments; IFBD, IF-binding domain; LCL, lymphoblastoid cell line; ODED, oculo-digito-oesophageal-duodenal; PA-JEB, junctional epidermolysis bullosa with pyloric atresia; PBL, peripheral blood lymphocytes; RPMI medium, Roswell Park Memorial Institute medium 
human plectin gene..$^{27}$ No human disease associated with alterations in the BPAGI gene has been reported so far.

We describe a girl with a balanced $t(6 ; 15)$ translocation showing profound cognitive and motor delay and tracheooesophageal atresia. The abnormal phenotype of the proposita is presumably associated with the breakpoint on chromosome 6 since no protein-coding genes have been found on the short arm of chromosome 15. The translocation's breakpoint interrupts the BPAGl gene just downstream of the end of the BPAGle isoform coding region, selectively disrupting the BPAGla and $\mathrm{b}$ isoforms.

\section{CASE REPORT}

The proband, now 4 years old, was the first child born to African healthy unrelated parents. During pregnancy the mother presented threatened abortion and polydramnios. Antenatal ultrasound screening revealed oesophageal atresia and a single umbilical artery. The baby was delivered by elective caesarean section at the 35th week of gestational age. Birth weight was $2200 \mathrm{~g}$ ( 25 th-50th centile). The diagnosis of oesophageal atresia was confirmed due to failure to pass a nasogastric tube into the stomach (the tube stopped $9 \mathrm{~cm}$ from the gingival margin) and through radiological studies of the upper oesophageal pouch (projection of end at level of D1-D2).

The absence of other congenital anomalies lead to classification of the newborn under the group A risk of the Waterston classification. ${ }^{29}$ Surgical correction was performed in the lst day of life. A right side transpleural thoracotomy was carried out, the distal tracheo-oesophageal fistula was closed, and a primary oesophageal anastomosis was performed. The anomaly was classified as a long gap oesophageal atresia with distal tracheo-oesophageal fistula (type 3 of the Roberts classification ${ }^{30}$ ).

Postoperative course was complicated by gastro-oesophageal reflux irresponsive to medical therapy. A subsequent oesophago-gastro-duodenal endoscopy demonstrated low grade oesophagitis and an accessory pancreatic duct opening in the stomach. A fundoplication surgical procedure was carried out when the baby was 1 year old due to the presence of severe gastro-oesophageal reflux. At 3 year follow up the patient can eat without problems.

From a neurological point of view, the child presented a non-progressive encephalopathy, characterised by mild pyramidal and cerebellar signs (hyperreflexia, muscle hypotonia, and truncal ataxia), severe motor and mental retardation, and delayed visual maturation. During the lst year of life prominent neurological signs were severe visual impairment and motor and cognitive delay, associated with mild muscle hypotonia and increased tendon reflex. At this time ophthalmologic examination was normal but visual evoked potentials were delayed and reduced in amplitude; brain MRI documented mild cerebral atrophy, without other malformations or abnormalities of visual pathways or of the posterior fossa. EEG revealed bursts of slow waves during wake and sleep; brainstem evoked potentials were normal; echocardiography was normal. The child's psychomotor development has been characterised by very slow improvement of motor abilities (independent walking was achieved at 30 months), and by the acquisition of minimal cognitive and linguistic abilities. Basic visual functions (visual acuity, fixation, and visual pursuit) have progressively improved, while visual evoked potentials normalised by the age of 12 months, supporting the diagnosis of delayed visual maturation. The child is now 4 years old, and on neurological examination presents mild hyperreflexia, gross motor incoordination and gait ataxia, severe visual inattention, and mildly reduced visual acuity. Her mental age, measured using the Griffiths scale, ${ }^{31}$ is less than 1 year (severe mental retardation): she is able to recognise familiar persons, sometimes smiles in response to smiles, but does not usually attempt to interact with others. Some utterances are present, but she does not usually use words in a meaningful way and her expressive language is limited to a pre-speech level (crying and vocalising but no use of gesture or imitative behaviour). She shows no interest in toys. EEG, and visual and brainstem evoked potentials are within normal limits. The child has no skin abnormalities, and no problems with wound healing were reported.

\section{METHODS}

\section{Cytogenetic characterisation}

Routine cytogenetic analysis was performed on the proband's blood using standard high-resolution techniques ${ }^{32}$ and DADAPI staining. Fluorescent in situ hybridisation (FISH) was done with a commercial (Vysis) mixture of probes including CEP 15 (D15Zl: 15p), SNRPN (15ql1-q13), and PML (15q22) according to the supplier's instructions and with PAC (P1 artificial chromosome) RP1-61B2 containing the gene BPAG1 (6p12.1: NCBI Map Viewer, http:// www.ncbi.nlm.nih.gov; Santa Cruz Human Genome Browser, http://genome.cse.ucsc.edu/cgi-bin/hgGateway/; The Wellcome Trust Sanger Institute, http://www.sanger. ac.uk). The PAC was labelled with biotin-dUTP (Vector Laboratories, Burlingame, CA) using standard nick translation and visualised with FITC-avidin (Vector) and the chromosomes were counterstained with DAPI (Sigma Aldrich, Milan, Italy).

Parents' karyotypes were analysed in G-banding.

\section{Generation of somatic cell hybrids}

The HPRT-negative RJK88 Chinese hamster cell line was maintained in Dulbecco's modified Eagle medium (DMEM) supplemented with 10\% fetal bovine serum (FBS; Gibco). A lymphoblastoid cell line (LCL) was generated from the proband's peripheral blood lymphocytes (PBL) with Epstein-Barr virus (EBV), and maintained in Roswell Park Memorial Institute (RPMI) medium supplemented with 10\% FBS (Gibco). RJK88 cells were seeded at a concentration of $2 \times 10^{7}$ cells per $100 \mathrm{~mm}$ tissue culture dish. After $24 \mathrm{~h}$, cells were washed with DMEM without serum, and $5 \times 10^{7} \mathrm{LCL}$ cells were added in $5 \mathrm{ml}$ of DMEM without serum containing $125 \mu \mathrm{l}$ of a $1 \mathrm{mg} / \mathrm{ml}$ stock of phytohaemagglutinin-P (Sigma). Dishes were incubated at $37^{\circ} \mathrm{C}$ for $15 \mathrm{~min}$. The media were gently aspirated, and $2 \mathrm{ml}$ of $50 \%$ polyethylene glycol (1000 MW; Sigma) was layered over each dish. After 1 min treatment, cells were washed three times with DMEM and incubated in $10 \mathrm{ml}$ of serum-free DMEM at $37^{\circ} \mathrm{C}$ for $30 \mathrm{~min}$. Cells were allowed to recover overnight in $10 \mathrm{ml}$ DMEM, 10\% FBS. The next day cells from each $100 \mathrm{~mm}$ dish were trypsinised and seeded 1:5 into fresh $100 \mathrm{~mm}$ dishes containing selective media composed of DMEM with $10 \%$ FBS and a $1 \times$ solution of hypoxantine-aminopterin-thymidine (HAT; Sigma). Cells were fed fresh selection media every 2-3 days. After 2-3 weeks, individual colonies were transferred to a 24 well plate end expanded in duplicate 6 well plates. One well was used for genomic DNA isolation and genotyping, while the other was used for freezing of the clone. Clones were maintained in HAT media throughout the experiment.

\section{DNA extraction and genotyping}

Genomic DNA of the proband and her mother was extracted from venous blood using standard protocols. DNA from hybrid clones was extracted with Isoquick (Orca Research, Bothell, WA). Genotyping of polymorphic loci was performed by amplification with primers labelled with fluorescent probes (ABI 5-Fam, Hex, and Tet) followed by analysis on 
a ABI 310 Genetic Analyzer (Applied Biosystems). Nonpolymorphic loci were assayed by electrophoresis on agarose gels. The UCSC Genome Browser (accessed June 2002) maps and sequence were used as references. Amplifications were performed with Taq Gold (Applied Biosystems) using standard protocols.

Inverse PCR was performed on RsaI cut, ligated (in $1 \mathrm{ml}$ volume to facilitate self-ligation of individual fragments) genomic DNA, using nested sets of primers at different positions. Amplified fragments were isolated on a $1 \%$ agarose/TAE gel, purified with Qiaex II, and sequenced with a BigDye Terminator Cycle Sequencing Kit (Applied Biosystems). Sequencing reactions were performed with a BigDye Terminator Cycle Sequencing Kit (Applied Biosystems) and run on an ABI Prism 310 Genetic Analyzer.

\section{RNA extraction and expression analysis}

Total RNA was extracted from tissues and cell lines with Eurozol (Euroclone) following the manufacturer's protocols, and human tissues total RNA was purchased from Clontech. cDNA synthesis was performed with Ready-To-Go You-Prime First strand beads (Amersham) and random hexamers. cDNA amplifications were performed in $25 \mu \mathrm{l}$ reactions, using JumpStart Red ACCUTaq LA DNA polymerase (Sigma) and the following protocol: $1 \mathrm{~min}$ at $96^{\circ} \mathrm{C}, 30$ cycles of $30 \mathrm{~min}$ at $94^{\circ} \mathrm{C} / 2 \mathrm{~min}$ at $68^{\circ} \mathrm{C}, 5 \mathrm{~min}$ final elongation time. The primers for allele-specific expression analysis were hBPAGl For (5' TTCAAGTTCATGGACCTAAGGACT 3'), SNP-E35/1F (5' CCGCTGAAAGAGAACTGGA $\left.3^{\prime}\right)$, and SNP-E35/1R CTGGAGGGCATTAAGTTCATA $3^{\prime}$ ); the primers for isoforms-specific amplification were hBPAGl For, hBPAGle Rev (5' TTTCCTCCAACTGATTGCGAAAATTCAG 3'), hBPAGl a Rev (5' AATTAGGCGGTTTTCAGTTTGGGTAAGA 3'), and hBPAGl b Rev (5' ATGAGGCCTCTTAAAACTGCTTGAAAG $\left.3^{\prime}\right)$. Control human G3PDH primers were from Clontech. The cDNA for 5' RACE was synthesised and amplified using a Smart RACE cDNA amplification kit (Clontech).

\section{RESULTS}

Cytogenetic and molecular characterisation

Cytogenetic analysis of the proposita revealed a reciprocal translocation interpreted as $\mathrm{t}(6 ; 15)(\mathrm{pl} 1.2 ; \mathrm{pl} 2)$ (fig lA). DADAPI staining showed that the 15p DA-DAPI positive region was still present on the $\operatorname{der}(15)$ (data not shown). FISH analysis confirmed the presence of satellite III DNA on the der(15) (fig 1B). Parents' karyotypes were normal.

We screened 80 hybrid clones and found two containing a normal chromosome 6, two with a $\operatorname{der}(6)$, and one with a der(15). Genotyping the proband, her mother, and representative hybrid clones for polymorphic markers on both sides of the breakpoint (table 1) demonstrated that the translocation had taken place on the paternal chromosome. FISH analysis confirmed that the chromosome 6 breakpoint was within PAC RP1-61B2, which gives three signals localised at the normal chromosome 6 and at both derivatives, respectively (fig 1C).

Based on the UCSC map, we typed the informative hybrid clones for chromosome 6 markers and eventually restricted the breakpoint location to a $400 \mathrm{bp}$ region about $2 \mathrm{~kb}$ downstream of the polyadenylation site of the BPAGle isoform (fig 2A). The breakpoint was cloned by inverse PCR from the proband's genomic DNA (fig $2 \mathrm{~B}$ ). There is no known feature on chromosome 6 that could be directly responsible for the translocation, except for an Alu repeat immediately flanking the breakpoint. All attempts to obtain additional chromosome 15 breakpoint sequence information by inverse PCR with other restriction enzymes failed.

The breakpoint does not disrupt the portion of BPAGI coding for the epithelial isoform, but selectively interrupts the two longer isoforms recently demonstrated in the mouse. ${ }^{7}$

We sought to analyse whether the translocation also affects the expression of the epithelial isoform of the gene and searched for informative polymorphisms in its coding region. We found a heterozygous G/A polymorphism (dbSNP rs\# cluster id: rs2230862, http://www.ncbi.nlm.nih.gov/ entrez/query.fcgi? $\mathrm{db}=\mathrm{snp}$ ) in the first of the two exons
A
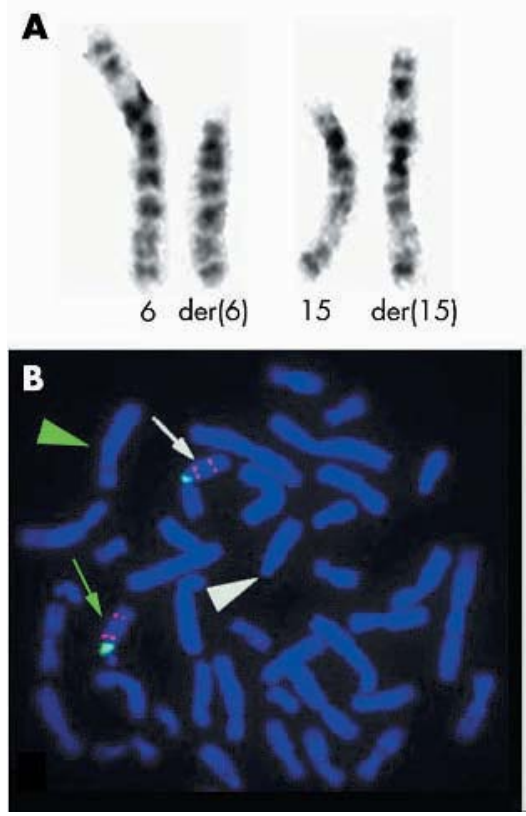

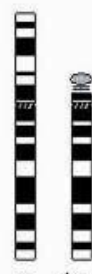

$6 \operatorname{der}(6)$

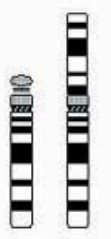

$15 \operatorname{der}(15)$

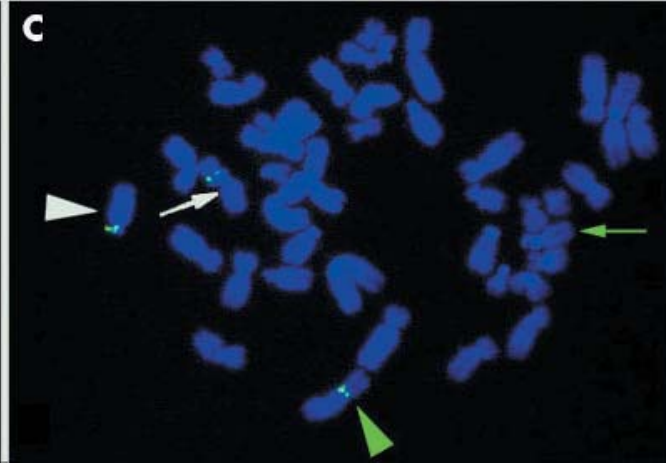

Figure 1 Cytogenetics and FISH results of the proband's lymphocytes. (A) Cut-out (left) and ideogram (right) of the normal (on the left) and the derivative (on the right) chromosomes 6 and 15. (B) FISH with probes D15Z1 (green signals), SNRPN (red signals close to the green signals), and PML (red distal signals) shows that the chromosome 15 breakpoint is on the short arm, distal to satellite III (D15Z1). (C) FISH with PAC RP1-61B2 demonstrates that the chromosome 6 breakpoint is within this clone. In B and C arrowheads indicate the normal chromosome 6 (green arrowhead) and the der(6) (white arrowhead), while arrows indicate the normal chromosome 15 (green arrow) and the der(15) (white arrow). 
Table 1 Molecular genotyping of the proband and her mother for informative chromosome 6 polymorphisms

\begin{tabular}{lllccc}
\hline Locus & Proband & Mother & Chr. 6 clone & der(15) clone & der(6) clone \\
\hline D6S459 & $89 / 91$ & $89 / 97$ & 89 & 91 & \\
D6S452 & $262 / 266$ & $266 / 268$ & 266 & 262 & 160 \\
D6S455 & $149 / 160$ & $145 / 149$ & 149 & & 228 \\
D6S430 & $228 / 232$ & 232 & 232 & & \\
\hline
\end{tabular}

Chr., chromosome. The father's DNA was not available. Typing of representative fusion hybrid clones is also shown.

coding for the rod domain of the BPAGle isoform, and determined the genotype of the alleles on the normal chromosome 6 (it carries the G allele) and the der(6) (it carries the A allele). Then we analysed the expression of the BPAGle isoform in the proband's LCL cells and hair roots (fig 3). We also analysed some heterozygous control subjects. The proband's LCL amplifies BPAGle cDNA about ten times more than the control LCL cells (fig 3A) and expresses exclusively the der(6) allele (fig 3B); hair roots express both alleles, although the allelic ratio varied between experiments, probably due to the small amount of RNA available.
Next, we analysed the expression of BPAG1 isoforms in a number of human tissues (fig 4A) using isoform-specific PCR (as in Leung 2001, modified for the human gene ${ }^{7}$ ). Sequence analysis of isoforms-specific amplification products and 5'RACE experiments (not shown) demonstrated that the alternative splicing pattern seen in the mouse BPAGl gene is maintained in humans. BPAGle is expressed in prostate and trachea; BPAGla is expressed predominantly in brain and cerebellum, but also in prostate, testis, and trachea; BPAGlb is the only isoform found in lung and skeletal muscle, but is also expressed in brain, prostate, testis, and trachea. We also

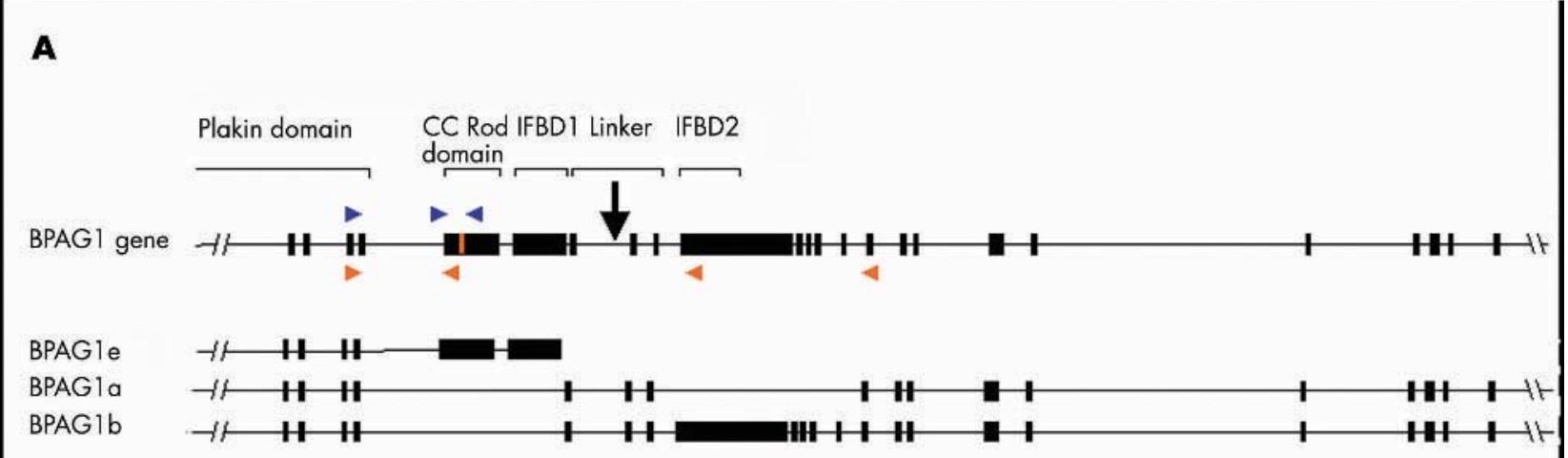

B

Chr.6 TAGGTATGCAGACCCAGAATAAAGAATTCTagctgagagcagtggctcatgcctgtaatcccagcactttgggaggccaaa

der(6) GTACAATATAATCTA Tagctgagagcagtggctcatgcctgtaatcccagcactttgggaggccaaa

$\operatorname{der(15)}$ TAGGTATGCAGACCCAGAATAAAGA TACCAAAGTAC

Figure 2 (A) BPAG1 gene and transcript's partial structure. The BPAG1 gene is shown in cen-tel orientation. Transcription of the BPAG1 gene is left to right. Only the portion of the gene close to the breakpoint is shown. The gene structure was obtained by combining the UCSC map data (based mainly on Okumura et al $2001^{8}$ ) and the mouse gene structure elucidated by Leung et al (2001). The protein domains corresponding to each gene region are shown on top. The location of all primers used for allele-specific expression analysis is indicated by blue arrowheads, while the position of the informative SNP is indicated by an orange bar in the CC rod domain exon; the primers used for isoform-specific expression analysis are represented by orange arrowheads. The breakpoint's location is indicated by a vertical arrow. (B) Breakpoint sequences. Chromosome 15-derived sequences are underlined; an AluJB repeat close to the breakpoint location on chromosome 6 is shown in lowercase letters; there is no ATTTC sequence on either derivative chromosome. 


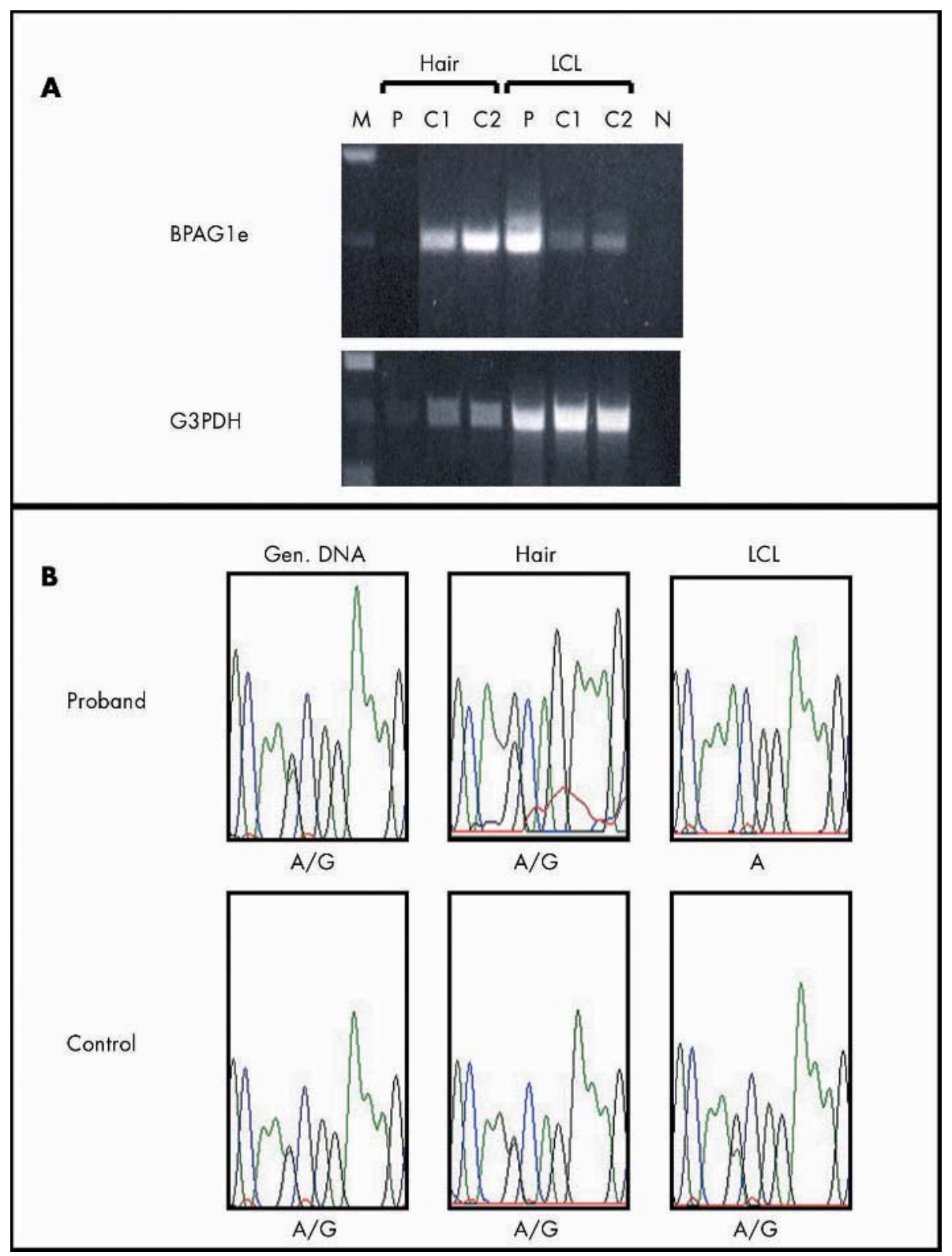

Figure 3 (A) Expression of BPAGle in hair and LCL samples. BPAGle and G3PDH amplifications were performed as described in Methods. $\mathrm{Cl}-\mathrm{C} 2$, control subjects; $M$, molecular weight marker $X$ (Roche Diagnostics, Monza, Italy); $P$, proband. (B) Allele-specific expression of BPAGle in tissues from proband and control $(\mathrm{Cl})$. All sequences show the coding strand of the gene. Genomic amplification was performed with primers SNP-E35/1F and SNP-E35/1R, cDNA amplification with hBPAG1 For and SNP-E35/1R.

analysed the expression of BPAG1 isoforms in oesophagus samples from normal controls. All BPAG1 isoforms are expressed in normal oesophagus, while the oesophageal epithelium expresses mainly the e form (fig 4B).

\section{DISCUSSION}

The child we studied carries a de novo balanced translocation associated with oesophageal atresia and cognitive and motor delays.

Reciprocal translocations associated with Mendelian phenotypes have been instrumental in the identification of many disease genes. ${ }^{33}$ Breakage of one or both chromosomes can cause loss of function phenotypes by disrupting the coding sequence of dosage-sensitive genes (see for example elastin and supravalvular aortic stenosis ${ }^{34}$ ) or by separating the genes from the nearby regulatory sequences (see for example SOX9 and campomelic dwarfism ${ }^{35}$ ). Alternatively, the translocation may cause gain of function phenotypes by switching the regulatory sequences from one gene to another, thus leading to inappropriate expression, or by producing a chimeric gene coding for a new chimeric protein. This is a common mechanism leading to tumour processes in leukaemias, lymphomas, and sarcomas (for a review see Rego and Pandolfi, 2002 ${ }^{36}$ ). In other cases one of the breakpoints of the chromosomes involved in the reciprocal translocation lose submicroscopic portions containing dosage-sensitive gene(s) (see for example SOX2 and anophthalmia ${ }^{37}$ ). In our case, the abnormal phenotype of the proposita was presumably associated with the breakpoint on chromosome 6 since no protein-coding genes are present on the short arm of chromosome 15. The p-arms of human acrocentric chromosomes contain organised arrays of beta-satellite and D4Z4 repeats and rDNA. The beta-satellite and D4Z4 repeats appear at the distal end of the arm, while rDNA and D4Z4 repeats are 
A

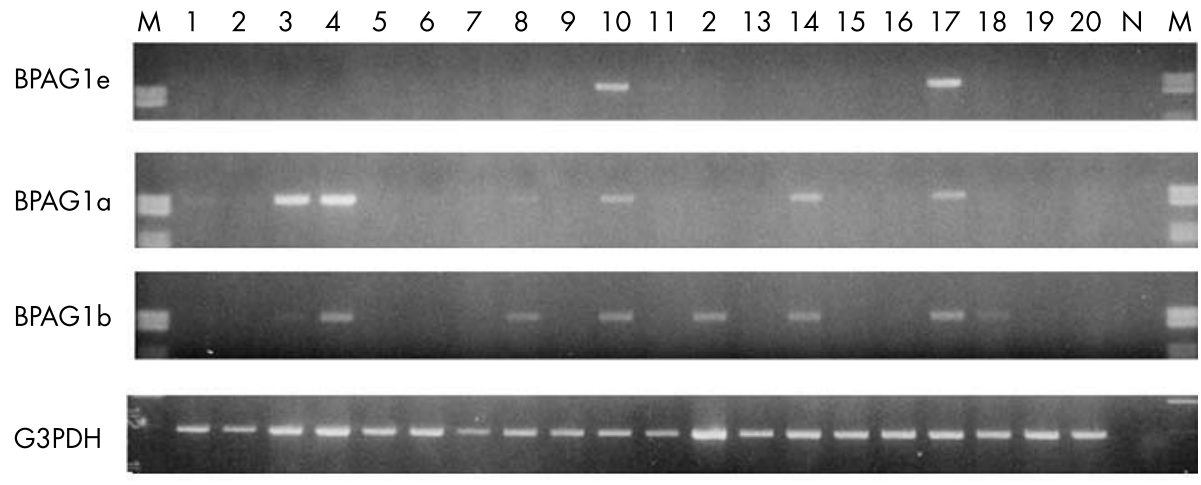

B

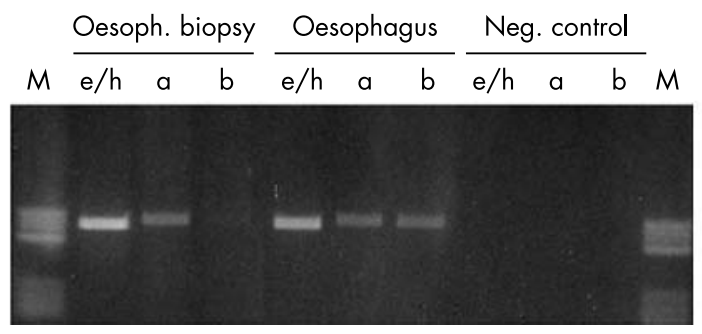

Figure 4 Expression of BPAG1 isoforms in human tissues. (A) 1: Adrenal gland; 2: bone marrow; 3: brain, cerebellum; 4: brain (whole); 5: heart; 6: kidney; 7: liver; 8: lung; 9: placenta; 10: prostate; 11: salivary gland; 12: skeletal muscle; 13: spleen; 14: testis; 15: thymus; 16: thyroid gland; 17 : trachea; 18: uterus; 19: colon; 20: small intestine. Molecular weight markers (M) are always Marker V for BPAG1 isoforms and Marker X for G3PDH (Roche, Diagnostics, Monza, Italy). (B) Expression in oesophageal lining (adult female, biopsy) and whole oesophagus.

interspersed at a more proximal location, corresponding to the pl2. ${ }^{38}{ }^{39}$ The finding that at the chromosome 6 breakpoint the BPAGI gene was interrupted resulting in the disruption of both brain- and muscle-specific isoforms suggests that $B P A G 1$ haploinsufficiency may cause the patient's clinical symptoms, or a truncated form of BPAGl a/b could be expressed in tissues and interfere with the activity of the wild type protein, leading to a dominant negative phenotype. Of course, we cannot exclude that the maternal BPAGl allele carries a mutation, leading to a recessive phenotype, or that the proband's phenotype is unrelated to the translocation.

The genomic organisation of the human and mouse BPAG1 genes is very similar, ${ }^{68}$ and our expression data on the three isoforms closely parallel those obtained in the mouse.

Dystonia musculorum $(\mathrm{dt})$ is a recessively inherited neurodegenerative disease in mice, first visible between 7 and 10 days after birth. It develops as a progressive ataxia, due to the degeneration of the sensory neurons in the CNS. ${ }^{2}$ The animals also show intrinsic muscle weakness and instability of skeletal muscle cytoarchitecture, as well as reduced resistance of stratified epithelia to mechanical stress. $^{25} 26$ In the $\mathrm{dt} / \mathrm{dt}$ mouse, lack of BPAGl probably induces a slow, initially subtle disorganisation of the developing neuronal cytoskeleton, eventually leading to disruption of the normal axioplasmic flow, resulting in focal swelling and neurodegeneration. Heterozygous mice apparently do not show any impairment. However, Bernier and colleagues $^{40}$ analysed the effects of dystonin mutations on Schwann cell structure and myelination of nerve fibres, and observed structural abnormalities and myelination defects. They also noted a gene dosage effect with heterozygous animals presenting hypo- and hyper-myelinated peripheral nerves.

The lack of one copy of BPAGl or the presence of truncated forms of the protein could produce a subtler effect in humans on the same structures, perhaps leading to a partial disorganisation of the sensory and motor circuits. In our patient, the translocation is associated with a profound delay in the acquisition of cognitive and motor skills, as well as in visual maturation. No effects on epithelial tissues are visible, in agreement with the finding that the BPAGI epithelial isoform is not disrupted by the translocation. When we tested allele-specific expression of the BPAGle isoform in order to assess whether any position effect might prevent transcription of the der(6) allele, we could show that both alleles are expressed in the proband's hair roots. Unexpectedly, proband's LCL generated very high levels of BPAGle amplification, apparently all from the $\operatorname{der}(6)$ allele. It is tempting to speculate that the unusual level of expression in LCL may be related to the presence on the $\operatorname{der}(6)$ chromosome of sequences from $15 \mathrm{p}$. Our cytogenetic analysis has demonstrated that the $15 \mathrm{p}$ breakpoint is located in the band containing rDNA and D4Z4 repeats. D4Z4 repeats are involved in the genesis of facioscapulohumeral muscular dystrophy (FSHD), and numerous studies have demonstrated their role in chromatin structure control (reviewed in Bickmore and van der Maarel, $2003^{41}$ ), while rDNA localises to the nucleolus in interphase cells.

To our knowledge, the effects of repeated sequences from the human acrocentric chromosome short arms on the expression of a nearby gene have not been analysed in a naturally occurring translocation or in a reporter gene construct.

Could the translocation also have caused or facilitated oesophageal atresia (EA) in the proposita? Congenital EA occurs in about three of 10000 live births ${ }^{42} 43$ as a result of faulty development of the primitive foregut. In over $90 \%$ of such cases tracheo-oesophageal fistula is also present. Most cases are sporadic, but familial cases do exist (reviewed in Van Staey et al, 19844). One dominant form of EA, the 
oculo-digito-oesophageal-duodenal (ODED) syndrome, has been mapped to chromosome $2 \mathrm{p} 23-24 .{ }^{45}$ Non-syndromic EA is considered to be a multifactorial trait whose pathogenesis and causation are ill defined. The recurrence of EA in some families suggests a contribution of genetic factors. The association of EA with cognitive and motor delay in the absence of other congenital anomalies has not been specifically described.

We have shown that all three BPAGl isoforms are expressed in the human adult trachea. BPAGle is expressed in the epithelial layer of the oesophagus, while the whole tissue expresses all three isoforms.

$B P A G 1$ expression in the developing digestive tract has never been analysed, and neither $d t / d t$ nor BPAGl KO mice show any obvious defects. On the other hand, there are data indicating a role for spectraplakins in organising morphogenetic events, such as the requirement for shot in the anastomosis of the developing tracheal tubules in Drosophila embryos, ${ }^{46}$ or the alteration of F-actin organisation by plectin. ${ }^{47}$

Genetic defects affecting the integrity of the basement membrane and hemidesmosomes can involve the digestive tract. This is the case in junctional epidermolysis bullosa with pyloric atresia (PA-JEB, MIM: 226730), an autosomal recessive disorder that can be caused by mutations in the integrin-beta-4 gene (ITGB4; MIM: 147557) and the integrinalpha-6 gene (ITGA6; MIM: 147556). Association with oesophageal atresia has been reported in very few cases. ${ }^{48} 49$

In view of the size of the BPAGl gene and its exceptionally complex structure, mutational analysis in subjects with oesophageal atresia is hardly feasible, but immunohistochemical analysis of surgically removed tissues may be an option.

This study describes the first human subject with a specific disruption of the brain- and muscle-specific isoforms of $B P A G 1$. The clinical picture of the patient is not easy to compare with the phenotype of the BPAGl-deficient mice, particularly in the absence of biochemical and histological data. Nevertheless, the pattern of expression of BPAGl supports the hypothesis that the patient's symptoms, and particularly her profound neurological impairment, are a direct consequence of the disruption of BPAGl brain and muscle isoforms, leading to insufficient or inappropriate production of protein during embryogenesis.

\section{ACKNOWLEDGEMENTS}

The authors are grateful to R Tonlorenzi for her gift of the RJK88 line and her help with the fusion hybrid protocol and to R Cagliani, M Sironi, and MT Bassi for critical reading of the manuscript.

\section{Authors' affiliations}

R Giorda, M C Bonaglia, C Baschirotto, IRCCS Eugenio Medea, Bosisio Parini, Lecco, Italy

A Cerritello, L Avolio, R Bragheri, O Zuffardi, IRCCS Policlinico San Matteo, Pavia, Italy

S Bova, G Lanzi, IRCCS Fondazione Casimiro Mondino, Pavia, Italy E Repetti, T Pramparo, P Maraschio, O Zuffardi, Biologia Generale e Genetica Medica, Università di Pavia, Pavia, Italy

S Giglio, IRCCS Ospedale San Raffaele, Milan, Italy

This work was supported by cofin02-MIUR (to OZ) and by the Italian Telethon Foundation (grant GPO247Y01 to OZ).

Conflict of interest: none declared.

Correspondence to: R Giorda, IRCCS Eugenio Medea, Via Don Luigi Monza, 20-23842 Bosisio Parini, Lecco, Italy; rgiorda@bp.Inf.it

Correspondence to: O Zuffardi, Biologia Generale e Genetica Medica, Via Forlanini, 14-27100 Pavia, Italy; zuffardi@unipv.it

Received 25 August 2003

Accepted for publication 6 September 2003

\section{REFERENCES}

1 Minoshima S, Amagai M, Kudoh J, Fukuyama R, Hashimoto T, Nishikawa T Shimizu N. Localization of the human gene for 230-kDa bullous pemphigoid autoantigen (BPAG1) to chromosome 6pter-q15. Cytogenet Cell Genet $1991 ; 57: 30-2$.

2 Brown A, Bernier G, Mathieu M, Rossant J, Kothary R. The mouse dystonia musculorum gene is a neural isoform of Bullous Pemphigoid Antigen 1. Nat Genet 1995; 10:301-6.

3 Brown A, Dalpe G, Mathieu M, Kothary R. Cloning and characterization of the neural isoforms of human Dystonin. Genomics 1995;29:777-80.

4 Guo LF, Degenstein L, Dowling J, Yu QC, Wollmann R, Perman B, Fuchs E. Gene targeting of BPAG1 abnormalities in mechanical strength and cell migration in stratified epithelia and neurologic degeneration. Cell 1995;81:233-43

5 Yang Y, Dowling J, Yu QC, Kouklis P, Cleveland DW, Fuchs E. An essentia cytoskeletal linker protein connecting actin microfilaments to intermediate filaments. Cell 1996:86:655-65.

6 Yang Y, Bauer C, Strasser G, Wollman R, Julien JP, Fuchs E. Integrators of the cytoskeleton that stabilize microtubules. Cell 1999;98:229-38.

7 Leung CL, Zheng M, Prater SM, Liem RKH. The BPAG1 locus: alternative splicing produces multiple isoforms with distinct cytoskeletal linker domains, including predominant isoforms in neurons and muscles. J Cell Biol $2001 ; 154: 691-8$

8 Okumura M, Yamakawa H, Ohara O, Owaribe K. Novel alternative splicing of BPAG1 (Bullous Pemphigoid Antigen 1) including the domain structure closely related to MACF (Microtubule Actin Cross-linking Factor). J Biol Chem 2002;277:6682-7.

9 Leung CL, Liem RK, Parry DA, Green KJ. The plakin family. J Cell Sci 2001;114:3409-10.

10 Hopkinson $\mathrm{SB}$, Jones JCR. The $\mathrm{N}$ terminus of the transmembrane protein BP180 interacts with the N-terminal domain of BP230, thereby mediating keratin cytoskeleton anchorage to the cell surface at the site of the hemidesmosome. Mol Biol Cell 2000; 11:277-86.

11 Leung CL, Sun D, Zheng M, Knowles DR, Liem RK. Microtubule actin crosslinking factor (MACF): a hybrid of dystonin and dystrophin that can interact with the actin and microtubule cytoskeletons. J Cell Biol 1999;147:1275-86.

12 Roper K, Gregory SL, Brown NH. The 'spectraplakins': cytoskeletal giants with characteristics of both spectrin and plakin families. J Cell Sci 2002:115:4215-25.

13 Okuda T, Matsuda S, Nakatsugawa S, Ichigotani Y, Iwahashi N, Takahashi M, Ishigaki T, Hamaguchi M. Molecular cloning of macrophin, a human homologue of Drosophila kakapo with a close structural similarity to plectin and dystrophin. Biochem Biophys Res Commun 1999;264:568-74.

14 Sun Y, Zhang J, Kraeft SK, Auclair D, Chang MS, Liu Y, Sutherland R, Salgia R, Griffin JD, Ferland LH, Chen LB. Molecular cloning and characterization of human trabeculin-alpha, a giant protein defining a new family of actinbinding proteins. J Biol Chem 1999;247:33522-30.

15 Becker S, Pasca G, Strumpf D, Min L, Volk T. Reciprocal signaling between Drosophila epidermal muscle attachment cells and their corresponding muscles. Development 1997;124:2615-22.

16 Prout M, Damania Z, Soong J, Fristrom D, Fristrom JW. Autosomal mutations affecting adhesion between wing surfaces in Drosophila melanogaster. Genetics 1997; 146:275-85.

17 Gregory SL, Brown NH. kakapo, a gene required for adhesion between and within cell layers in Drosophila, encodes a large cytoskeletal linker protein related to plectin and dystrophin. J Cell Biol 1998;143:1271-82.

18 Strumpf D, Volk T. Kakapo, a novel cyłoskeletal-associated protein is essential for the restricted localization of the neuregulin-like factor, vein, at the muscletendon junction site. J Cell Biol 1998;143:1259-70.

19 Walsh EP, Brown NH. A screen to identify Drosophila genes required for Integrin mediated adhesion. Genetics 1998;150:791-805.

20 Lee S, Harris KL, Whitington PM, Kolodziej PA. short stop is allelic to kakapo, and encodes rod-like cytoskeletal-associated proteins required for axon extension. J Neurosci 2000;20:1096-108.

21 Van Vactor D, Sink H, Fambrough D, Tsoo R, Goodman CS. Genes that control neuromuscular specificity in Drosophila. Cell 1993;73:1137-53.

22 Prokop A, Uhler J, Roote J, Bate M. The kakapo mutation affects terminal arborization and central dendritic sprouting of Drosophila motorneurons. J Cell Biol 1998;143:1283-94.

23 Gao FB, Brenman JE, Jan LY, Jan YN. Genes regulating dendritic outgrowth, branching, and routing in Drosophila. Genes Dev 1999;13:2549-61.

24 Bernier G, de Repentigny Y, Mathieu M, David S, Kothary R. Dystonin is an essential component of the Schwann cell cytoskeleton at the time of myelination. Development 1998; 125:2135-48.

25 Dalpé G, Mathieu M, Comtois A, Zhu E, Wasiak S, de Repentigny Y, Leclerc N, Kothary R. Dystonin-deficient mice exhibit an intrinsic muscle weakness and an instability of skeletal muscle cytoarchitecture. Dev Bio 1999:10:367-80

26 Hartmann N, Martrette J-M, Strazielle C, Westphal A. Dystonia muscolorum mutation and myosin heavy chain expression in skeletal and cardiac muscles. J Cell Biochem 1999:74:90-8.

27 McLean WH, Pulkkinen L, Smith FJ, Rugg EL, Lane EB, Bullrich F, Burgeson RE, Amano S, Hudson DL, Owaribe K, McGrath JA, McMillan JR, Eady RA, Leigh IM, Christiano AM, Uitto J. Loss of plectin causes Epidermolysis Bullosa with muscular dystrophy: cDNA cloning and genomic organization. Genes Dev 1996;10:1724-35.

28 Smith FJ, Eady RA, Leigh IM, McMillan JR, Rugg EL, Kelsell DP, Bryant SP, Spurr NK, Geddes JF, Kirtschig G, Milana G, de Bono AG, Owaribe K, Wiche G, Pulkkinen L, Uitto J, McLean WH, Lane EB. Plectin deficiency results 
in muscular dystrophy with epidermolysis bullosa. Nat Genet 1996;13:450-7.

29 Waterston DJ, Carter REB, Aberdeen E. Esophageal atresia: tracheoesophageal fistula: a study of survival in 218 infants. Lancet 1962;1:819-22.

30 Roberts KD, Carre IJ, Inglos MCN. The management of congenital oesophageal atresia-tracheo-oesophageal fistula. Thorax 1955;10:45-57

31 Griffiths R. The Griffiths mental development scales 1996 revision (revised by $M$ Huntley). Henley: Association for Research in Infant and Child Development, Test Agency, 1996.

32 Dutrillaux B, Viegas-Pequignot E. High resolution R- and G-banding on the same preparation. Hum Genet 1981;57:93-5

33 Bugge M, Bruun-Petersen G, Brondum-Nielsen K, Friedrich U, Hansen J, Jensen G, Jensen PK, Kristoffersson U, Lundsteen C, Niebuhr E, Rasmussen KR, Rasmussen K, Tommerup N. Disease associated balanced chromosome rearrangements: a resource for large scale genotype-phenotype delineation in man. J Med Genet 2000;37:858-65.

34 Curran ME, Atkinson DL, Ewart AK, Morris CA, Leppert MF, Keating MT. The elastin gene is disrupted by a translocation associated with supravalvular aortic stenosis. Cell 1993:73:159-68.

35 Pfeifer D, Kist R, Dewar K, Devon K, Lander ES, Birren B, Korniszewski L, Back E, Scherer G. Campomelic dysplasia translocation breakpoints are scattered over $1 \mathrm{Mb}$ proximal to SOX9: evidence for an extended control region. Am J Hum Genet 1999:65:111-24.

36 Rego EM, Pandolfi PP. Reciprocal products of chromosomal translocations in human cancer pathogenesis: key players or innocent bystanders? Trends Mol Med 2002;8:396-405

37 Fantes J, Ragge NK, Lynch SA, McGill NI, Collin JR, Howard-Peebles PN, Hayward C, Vivian AJ, Williamson K, van Heyningen V, FitzPatrick DR. Mutations in SOX2 cause anophthalmia. Nat Genet 2003;33:461-3.

38 Winokur ST, Bengtsson U, Vargas JC, Wasmuth JJ, Altherr MR. The evolutionary distribution and structural organization of the homeoboxcontaining repeat D4Z4 indicates a functional role for the ancestral copy in the FSHD region. Hum Mol Genet 1996;5:1567-75.
39 Piccini I, Ballarati L, Bassi C, Rocchi M, Marozzi A, Ginelli E, Meneveri R. The structure of duplications on human acrocentric chromosome short arms derived by the analysis of 15p. Hum Genet 2001;108:467-77.

40 Bernier G, Brown A, Dalpe G, de Repentigny Y, Mathieu M, Kothary R. Dystonin expression in the developing nervous system predominates in the neurons that degenerate in dystonia musculorum mutant mice. Mol Cell Neurosci 1995;6:509-20

41 Bickmore WA, van der Maarel SM. Perturbations of chromatin structure in human genetic disease: recent advances. Hum Mol Genet 2003; 12(2):R207-13

42 David TJ, O'Callaghan SE. Esophageal atresia in the south west of England. J Med Genet 1975;12:1-11.

43 Szendrey T, Danyi G, Czeizel A. Etiological study on isolated esophageal atresia. Hum Genet 1985;70:51-8.

44 Van Staey M, De Bie S, Matton MTh, De Roose J. Familial congenital esophageal atresia: personal case report and review of the literature. Hum Genet 1984;66:260-6.

45 Celli J, van Beusekom E, Hennekam RC, Gallardo ME, Smeets DF, de Cordoba SR, Innis JW, Frydman M, Konig R, Kingston H, Tolmie J, Govaerts LC, van Bokhoven H, Brunner HG. Familial syndromic esophageal atresia maps to 2p23-p24. Am J Hum Genet 2000:66:436-44

46 Lee S, Kolodziej PA. The plakin Short Stop and the RhoA GTPase are required for $E$-cadherin-dependent apical surface remodeling during tracheal tube fusion. Development 2002;129:1509-20.

47 Andrä K, Nikolic B, Stocher M, Drenkhahn D, Wiche G. Not just scaffolding: plectin regulates actin dynamics in cultured cells. Genes Dev 1998; 12:3442-51.

48 Carmi R, Sofer S, Karplus M, Ben-Yakar Y, Mahler D, Zirkin H, Bar-Ziv J. Aplasia cutis congenita in two sibs discordant for pyloric atresia. Am J Med Genet 1982;11:319-28.

49 Cetinkursun S, Ozturk H, Celasun B, Sakarya MT, Alpasian F. Epidermolysis bullosa associated with pyloric, esophageal, and anal atresia: a case report. J Pediatr Surg 1995;30:1477-8. 